\section{ONCOLOGISTS' PERSPECTIVES ON EVOLUTION OF FIRST-LINE IMMUNE CHECKPOINT INHIBITOR MAINTENANCE THERAPY IN MANAGEMENT OF ADVANCED UROTHELIAL CARCINOMA IN THE US}

${ }^{1}$ Petros Grivas, ${ }^{2}$ Phani Veeranki, ${ }^{3}$ Kevin Chiu, ${ }^{4}$ Vivek Pawar, ${ }^{5}$ Jane Chang, ${ }^{4}$ Murtuza Bharmal*. 'Department of Medicine, Division of Oncology, University of Washington, Seattle, WA, USA; Clinical Research Division, Fred Hutchinson Cancer Research Center, Seattle Cancer Care Alliance, Seattle, WA, Seattle, United States; ${ }^{2}$ PRECISIONheor, Los Angeles, CA, USA (At the time of the study), Los Angeles, CA, United States; ${ }^{3}$ PRECISIONheor, Los Angeles, CA, USA, Los Angeles, CA, United States; ${ }^{4}$ EMD Serono, Billerica, MA, USA, Billerica, MA, United States; ${ }^{5}$ Pfizer, New York, NY, USA, New York, NY, United States

Background Avelumab, a PD-L1 immune checkpoint inhibitor (ICI), was recently approved as first-line (1L) maintenance therapy for locally advanced/unresectable or metastatic urothelial carcinoma (aUC) after disease control with platinum-based chemotherapy. ${ }^{1}$ Given the evolving treatment landscape, the study aim was to gain real-world insights into clinical decision-making among oncologists for patients with aUC.

Methods In March 2021, a cross-sectional web-based survey was administered to a sample of US oncologists treating patients with aUC. Oncologists' demographics, practice characteristics, and treatment patterns were obtained; descriptive statistics were used.

Abstract 630 Table 1 Oncologists characteristics and considerations for $1 \mathrm{~L} \mathrm{ICl}$ maintenance therapy

\begin{tabular}{|l|l|l|}
\hline & $\begin{array}{l}\text { High } \\
\text { consideration } \\
\text { (1L ICI } \\
\text { maintenance for } \\
\geq 40 \% \text { of their } \\
\text { patients) } \\
\text { (N=118) }\end{array}$ & $\begin{array}{l}\text { Low consideration } \\
\text { (1L ICI maintenance } \\
\text { for <40\% of their } \\
\text { patients) } \\
\text { (N=33) }\end{array}$ \\
\hline Age, mean (SD), years & $49.8(10.1)$ & $49.9(10.5)$ \\
\hline Male, \% & 69.5 & 81.8 \\
\hline Practice location, \%* & & 12.1 \\
\hline Solo & 8.5 & 60.5 \\
\hline Group/partnership & 49.1 & 15.2 \\
\hline University & 30.5 & 12.1 \\
\hline Hospital & 10.2 & 18.2 \\
\hline Years of practice, \% & 18.6 & 57.6 \\
\hline$<10$ & 51.7 & 24.2 \\
\hline $11-20$ & 28.0 & $53.6(23.5)$ \\
\hline$>20$ & $54.4(21.0)$ & $32.0(21.5)$ \\
\hline $\begin{array}{l}\text { Cisplatin-eligible regimen, mean } \\
\text { \% ofpatients in practice (SD) }\end{array}$ & $30.1(16.3)$ & \\
\hline $\begin{array}{l}\text { Carboplatin-eligible regimen, mean } \\
\% \text { ofpatients in practice (SD) }\end{array}$ & & 15.2 \\
\hline $\begin{array}{l}\text { Number of cycles of chemotherapy } \\
\text { before initiating 1L ICI maintenance, \%* }\end{array}$ & 5.9 & 24.2 \\
\hline 2 & 19.5 & 42.4 \\
\hline 3 & 64.4 & 12.1 \\
\hline 4 & 16.1 & 36.4 \\
\hline 5 & 28.0 & \\
\hline 6 & & \\
\hline Responses not mutually exclusive. & & \\
\hline
\end{tabular}

Results The study included 151 medical oncologists, who reported that $54 \%$ and $31 \%$ of their patients, on average, would be classified as cisplatin or carboplatin eligible for their $1 \mathrm{~L}$ treatment, respectively. Approximately $78 \%$ of oncologists $(n=118)$ considered using ICI maintenance in $\geq 40 \%$ of their patients following disease control with platinum chemotherapy and were categorized as the "high-consideration" group, for further exploratory analysis; the rest $(22 \%)$ were in the lowconsideration group (See table 1). Approximately, 31\% and $27 \%$ of oncologists in the high- and low-consideration groups reported administering ICI maintenance with a 2-3-week gap after chemotherapy, while $45 \%$ and $46 \%$ reported administering it with a 4-6-week gap after chemotherapy, respectively.

Conclusions Surveyed oncologists reported that $85 \%$ of patients with aUC in US may be eligible for platinum-based chemotherapy. Further, $78 \%$ of the surveyed oncologists would consider 1L ICI maintenance therapy after disease control with platinum-based chemotherapy for over $40 \%$ of their patients. Future studies are warranted to evaluate real-world treatment patterns, barriers, and utilization of ICI maintenance therapy as the new $1 \mathrm{~L}$ standard of care.

Acknowledgements The authors would like to acknowledge all physicians at who participated and completed the survey for the study.

\section{REFERENCE}

1. Powles T, et al. N Engl J Med 2020;383(13):1218-1230.

Ethics Approval The study was reviewed and determined to be exempt by Advarra IRB.

Consent All survey participated signed a consent form.

http://dx.doi.org/10.1136/jitc-2021-SITC2021.630 